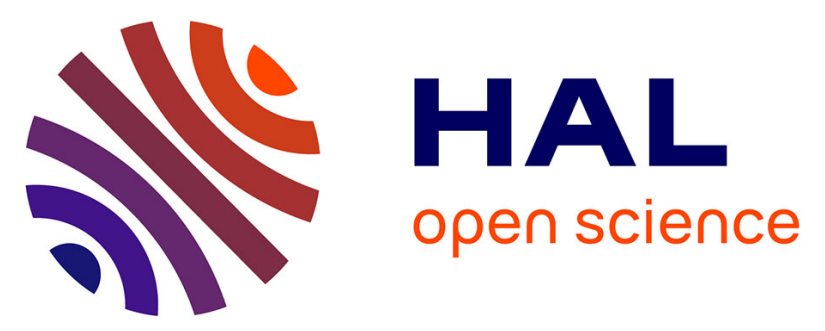

\title{
Towards parametric environmental profiles of complex industrial systems in preliminary design stage
}

\author{
François Cluzel, Bernard Yannou, Yann Leroy, Dominique Millet
}

\section{To cite this version:}

François Cluzel, Bernard Yannou, Yann Leroy, Dominique Millet. Towards parametric environmental profiles of complex industrial systems in preliminary design stage. ASME 2011 International Design Engineering Technical Conferences and Computers and Information in Engineering Conference - IDETC/CIE2011, Aug 2011, Washington, DC, United States. Paper no. DETC2011-47376, pp. 241-250, 10.1115/DETC2011-47376 . hal-00794628

\section{HAL Id: hal-00794628 \\ https://hal.science/hal-00794628}

Submitted on 26 Feb 2013

HAL is a multi-disciplinary open access archive for the deposit and dissemination of scientific research documents, whether they are published or not. The documents may come from teaching and research institutions in France or abroad, or from public or private research centers.
L'archive ouverte pluridisciplinaire HAL, est destinée au dépôt et à la diffusion de documents scientifiques de niveau recherche, publiés ou non, émanant des établissements d'enseignement et de recherche français ou étrangers, des laboratoires publics ou privés. 


\title{
Towards parametric environmental profiles of complex industrial systems in preliminary design stage
}

\author{
François Cluzel $^{1 *}$, Bernard Yannou ${ }^{1}$, Yann Leroy $^{1}$ and Dominique Millet ${ }^{2}$ \\ ${ }^{1}$ Ecole Centrale Paris, Laboratoire Genie Industriel, Chatenay-Malabry, France \\ ${ }^{2}$ SUPMECA Toulon, LISMMA, Toulon, France
}

\begin{abstract}
The eco-design of complex industrial systems becomes a major issue for the concerned companies. Life Cycle Assessment (LCA) in particular is more adapted to "classical" products such as consumer goods. Performing LCA of such systems requires some thoughts to ensure significant results, for example concerning data granularity and quality. This article proposes a Life Cycle Assessment of an Alstom Grid AC/DC conversion substation for the aluminium industry. This LCA integrates first answers to the previous limitations. Very interesting results permit to orient the ecodesign strategy of the company. Moreover they lead to imagine original ways to configure the system. Thus a first and simple parametric LCA model is proposed: four different electrical sources are used to analyze the sensitivity of the design factors to the environmental impacts of the substation. Based on design of experiments, a more advanced model of such a tool would permit to identify the best configuration in terms of environmental performance, costs and reliability.
\end{abstract}

Keywords: Eco-design, Life Cycle Assessment (LCA), Complex industrial system, parametric simulation, $A C / D C$ conversion substation.

\section{INTRODUCTION}

Due to the current highly competitive markets and the growing sustainable awareness, environmental considerations have become a more and more crucial topic in the industrial world. Even if this growing awareness is a consequence of the recent environmental regulations (for example the WEEE [1], RoHS [2] or EuP [3] European directives or the REACH [4] European regulation), many companies attempt to go further and to propose more eco-friendly products. This kind of eco-design proactive approach is often considered as an important competitive advantage [5]. Dealing first with mass consumer goods, eco-design now reaches B to B and large-scale systems, in particular energy systems.

Large scale systems are characterized by a high level of complexity during their whole life cycle. It means that those systems are complex in themselves, but also that the way to model them is complex too, for example in environmental assessment. Actually, if a methodology like Life Cycle Assessment (LCA) is clearly defined and well mastered for "classical" consumer goods, the way to model complex industrial systems is much fuzzier. Examples of such limits in LCA are data availability and quality, choice of the boundaries according to the engaged resources or the local impacts and their evolution in time $[6,7]$.

\footnotetext{
Contact author

E-mail: francois.cluzel@ecp.fr

Phone: +33141131328
} 
Examples of such systems are in particular energy systems, chemical facilities or industrial plants. This paper considers large electrical stations from Alstom Grid, called AC/DC conversion substations. This type of system is used in particular in primary aluminium smelters to convert the energy from the electrical network (high voltage) to energy usable for the electrolysis of aluminium (high current). It works continuously during 30 or 40 years. The life cycle of electrolysis substations is closely linked to the life cycle of the aluminium smelter, and, by extension, to the political and economic choices. This is a good example of a complex industrial system.

This paper proposes to study the limits associated to the eco-design of complex industrial systems, in particular in LCA. A global LCA of an Alstom Grid AC/DC conversion substation has been performed by considering these limits to identify its sensitivity to the major layout and design factors. This ensures a good orientation of the eco-design activities as well as a good environmental knowledge to optimize the system configuration at the preliminary design stage. Thus a crucial question appears: which ways are possible to configure and value such complex systems in an environmental perspective? Considering the main characteristics of the studied system and its implementation context, a preliminary model based on parametric simulations is proposed. It opens the possibility to develop environmental configurators from the LCA results.

Section 2 explores the limits of LCA for complex industrial system and presents the study, while Section 3 describes the Alstom Grid substations and highlights their complexity. A LCA of a substation is described in Section 4. Section 5 is devoted to the integration of parametric environmental profile simulations to define the best environmental configuration of the studied system in a given context. Finally, Section 6 offers conclusions and perspectives for future works that will be led in the next months.

\section{Life Cycle Assessment and complex industrial systems}

\subsection{Limits related to LCA}

Table 1. LCA problems by phase (from [6])

\begin{tabular}{lll}
\hline \multicolumn{1}{c}{ Phase } & \multicolumn{1}{c}{ Problem } \\
\hline Goal and scope definition & - Functional unit definition \\
& - Boundary selection \\
& - Social and economic impacts \\
& Alternative scenario considerations \\
\hline Life cycle inventory analysis & - Allocation \\
& - Negligible contribution ('cutoff') \\
& criteria \\
\hline Life cycle impact assessment & - Local technical uniqueness \\
& Impact category and methodology \\
& - Selection \\
& - Localial variation \\
& - Dynamics of the environment \\
& - Time horizons \\
\hline Life cycle interpretation & - Weighting and valuation \\
& - Uncertainty in the decision process \\
\hline All & - Data availability and quality \\
\hline
\end{tabular}


Life Cycle Assessment, defined in standards ISO 14040 [8] and 14044 [9] is a powerful environmental evaluation tool. Internationally recognized, it is widely used in large companies to drive the eco-design of their products.

However LCA stays a relatively young methodology and is therefore subject to some limitations that can degrade the quality and the credibility of the results. Reap at al. $[6,7]$ give a list of LCA problems by phase (see Table 1). The boundary selection, the spatial variation, the local environmental uniqueness and the dynamics of the environment are particularly important in this study. But data availability and quality are the major limitations of Life Cycle Assessment. This is particularly highlighted by Weidema and Wesnaes [10] or Leroy [11].

Another issue dealing with LCA is the fact that the assessment must be based on existing products [12]. Indeed, precise data are needed to feed the Life Cycle Inventory (LCI) phase, which does not match with products at a conceptual design stage.

\subsection{Dealing with complex industrial systems}

This paper focuses on complex industrial systems, whose specificities have not really been taken into account into LCA. These are industrial systems whose complexity induces major issues in terms of modeling, prediction or configuration. A complex industrial system in the sense of eco-design is:

- A large-scale system in terms of subsystems and components number, mass and resources use.

- A system whose life cycle is hardly predictable at the design level, in particular its life time, upgrades, maintenance and end-of-life at long-term.

- A system whose subsystems may have different life cycles and different obsolescence times.

- A system which is in close interaction with its environment (super system, geographic site...).

- A system supervised by human decisions and management.

Examples of such systems are in particular energy systems, like the Alstom Grid conversion substations described in Section 3. In front of such systems, the previously mentioned LCA limitations are amplified by the internal system complexity. In addition complementary issues appear, such as the quantification of the needed resources and, more globally, the organization of the project (deliverables, milestones, team...). We have already proposed the basis of an eco-design project management methodology for complex industrial systems [13].

Life Cycle Assessments of large-scale energy systems have already been performed (see for example $[14,15])$. However they are considered as "classical" products. Local parameters in particular, implying nature of electricity, seems for us crucial to approximate the real environmental impacts of these systems. The next sections propose to optimize the application of LCA for complex industrial systems.

\subsection{Presentation of the study}

This study was conducted at Alstom Grid in the Power Electronics Massy unit (France). The main characteristic of the PEM systems (mainly AC/DC conversion substation for aluminium smelters) is their uniqueness, in the sense that there is no standard product, but a global product family. The design of a substation is based on previous substations and could be very close to that previous ones, but the integration of the customer needs make the systems always different. These substations are described in more details in the next section.

The second main characteristic of this study is the fact that if one substation subsystem is designed at the PEM unit, the others come from other Alstom Grid units, or even suppliers and subcontractors, making the data collection particularly hard to perform. 
Six months were necessary to conduct a global LCA of a substation, with about one month to structure the project and define the scope and objectives, four months to collect the data, one month to collect and analyze the LCIA results and one last month to precisely document and capitalize the study.

The study was structured around predefined deliverables and milestones, such as a project charter, data inventory templates, a data quality procedure and a precise LCA report. Data quality was managed through a simplified approach based on pedigree matrices $[10,11,16]$. This approach allows an easy identification of the inventory weaknesses and it is then possible to improve its quality by directly working on these data.

Data granularity, that means the extent to which the system is broken down into small parts, was chosen to permit the identification of the main environmental impacts on the whole substation life cycle, without spending too much time to collect the data. Limitations and weaknesses of the study were rigorously documented to facilitate the analysis and ensure the quality of future works.

Next section describes the Alstom Grid AC/DC conversion substations and their implementation context by highlighting their complexity. The LCA is then presented in Section 4.

\section{AC/DC conversion substation: a complex industrial system}

To understand the context of Alstom Grid AC/DC conversion substations for the aluminium industry, it is necessary to give some details about primary aluminium production.

\subsection{Aluminium electrolysis}

Primary aluminium production is based on the Hall-Héroult process discovered in 1886, using aluminium electrolysis. This process follows different steps identified on Figure 1. We focus in this section on the aluminium electrolysis stage.

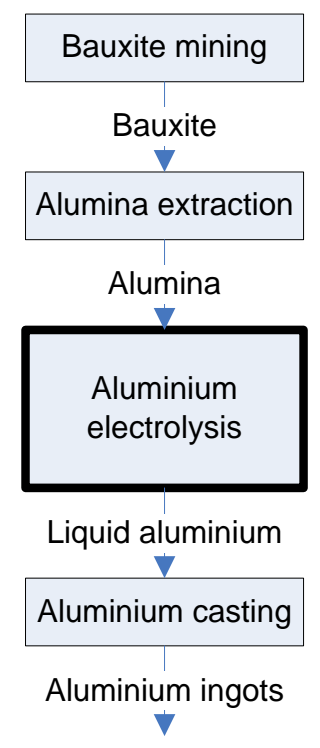

Figure 1. Primary aluminium production

An aluminium smelter includes the aluminium electrolysis and casting steps of the primary aluminium production. It is particularly energy-intensive: actually the amount of energy consumed by a state-ofthe-art primary aluminium plant is comparable to the amount of energy delivered by a nuclear plant unit, or consumed by a large city like Marseille (850,000 people), namely more than $1 \mathrm{GW}$. Given the electrical needs of such a plant, the furniture of energy is often realized by a captive power plant or a 
specific contract with energy producers. High cost and intermittent energies are not adapted to the electrolysis process, which must imperatively run continuously (24 hours a day) at an effective cost. That is why the current smelters mainly work with fossil energies (coal, natural gas, e.g. in India, China or Persian Gulf countries), hydro energy (e.g. in Canada, Iceland, Norway, Russia...) or nuclear power (e.g. French electrical mix).

The smelter is moreover often located near consequent transportation ways to import alumina and export aluminium (harbors - even captive harbors -, roads, rail tracks).

A generic smelter (see Figure 2) consists in:

- Potrooms that contains hundreds of electrolysis pots (commonly between 200 and 400 in a one-kilometer long building),

- A casthouse,

- An electrode plant that produces anodes for the electrolysis process,

- An AC to DC conversion substations that supplies energy to the potlines from the grid,

- Some other elements such as storage and auxiliaries buildings, silos or transportation facilities.

Despite great improvements in the last decades, the environmental impacts associated with aluminium electrolysis stay really huge $[14,17]$. It is mainly due to $\mathrm{CO} 2$ emissions from the electrolysis pots and to energy consumption. Environmental considerations are then a major issue for aluminium producers, and the energy-related subsystems clearly need to be improved.

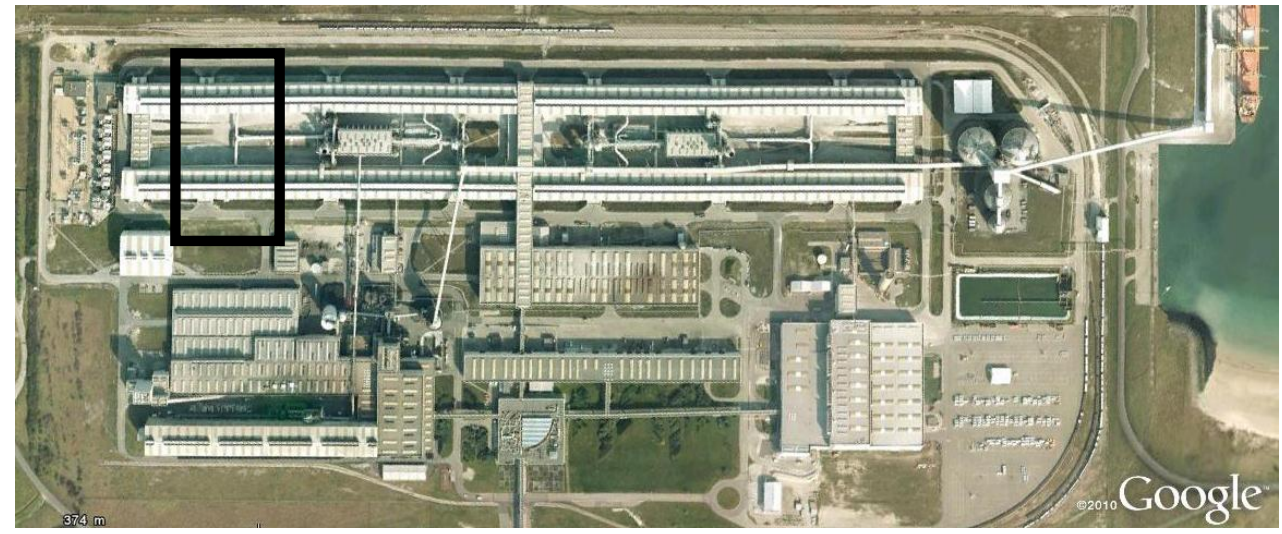

Figure 2. Aluminium Dunkerque, France (@2010 Google). The substation is surrounded by a rectangle.

The conversion substation is a key element of an aluminium smelter, as it permits to convert energy from the high voltage networks to energy usable from aluminium electrolysis. We focus in the next paragraph on this substation.

\subsection{Electrolysis substation}

PEM (Power Electronics Massy) is a unit of Alstom Grid, global player in electrical transmission all around the world. This unit designs, assembles and sells in particular AC/DC conversion substations for aluminium smelters worldwide. These are electrical stations to convert energy from the high voltage network to energy usable for the electrolysis of aluminium.

An aluminium electrolysis substation is made of thousands tons of power electronics components and transformers, for a cost of several dozens of million Euros. It is classically composed of several groups (including at least one redundancy), themselves composed of a regulating transformer, a rectifier transformer and a rectifier, as well as other smaller equipments. Figure 3 shows an example of a substation with 4 groups. The groups are connected on one side to the high voltage network through a 
high voltage substation (air or gas insulated, AC current), and on the other side to a busbar that is directly connected to the electrolysis potline (composed of hundreds of electrolysis pots, DC current). Filters are also added to the assembly to protect the network against harmonics. All the groups are supervised by control elements that are connected to the electrolysis pots to regulate the process.

The life time of this type of substations is really long, up to 30 or 40 years. No end-of life scenario is clearly defined as it is in charge of the customer (and it varies from one country to another). Moreover great uncertainties appear during the use phase: maintenance operations, dysfunctions, updates or revamping operations are not regular and they stay dependent on the economic situation and the aluminium producer investment policies.

In short, an AC/DC conversion substation for the aluminium electrolysis appears as a complex industrial system with close links to the primary aluminium production processes. In the context of ecodesign deployment at Alstom Grid PEM, a first LCA has been conducted on an instantiation of an electrolysis substation in India. This study is detailed in the next section. The analysis of the sensitivity of the layout and design factors will permit to identify environmental improvement ways through creativity sessions. It will also ensure good choices to configure the system at the preliminary design stage.

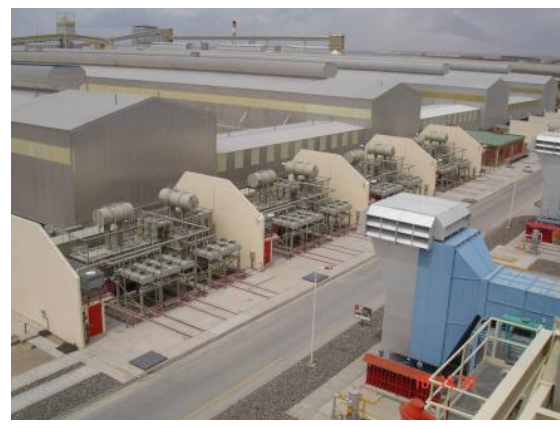

Figure 3. Example of an Alstom Grid aluminium electrolysis substation (Aluar smelter, Argentina)

\section{LCA of an electrolysis substation}

This section is divided in three paragraphs corresponding to the three first phase of a LCA approach [8]: objectives and scope, Life Cycle Inventory (LCI) and Life Cycle Impact Assessment (LCIA).

\subsection{Objectives and scope of the study}

The main objective of this LCA study is the identification of the main environmental impacts of a substation life cycle in order to identify projects to improve its environmental performance. So its purpose is to orient the future eco-design activities that will be conducted at Alstom Grid PEM.

The study is focused on an Alstom Grid AC/DC conversion substation that has been designed and is currently under construction for the Hindalco Mahan aluminium smelter. The whole life cycle of the substation will be considered. This substation is composed of five groups.

The Hindalco Mahan aluminium smelter (under construction too) is located in central India (Bargawan, state of Madhya Pradesh). It is characterized by a captive coal power plant ( $900 \mathrm{MW}$ ) and is designed to produce 360,000 tons of primary aluminium per year with modern electrolysis pots.

Considering the constraints and characteristics of such a project, the following functional unit has been considered: "To ensure for 30 years without interruption the conversion of $220 \mathrm{kV}_{A C}$ high voltage energy to energy usable for aluminium electrolysis (360 $\left.k A_{D C}, 1650 V_{D C}\right)$ according to the Hindalco 
specifications". This functional unit is adapted to our needs, namely to feed internal eco-design works on substations. The substation life time is 30 years, which means that the reference flow is 1.

The substation has been broken down into 8 subsystems: regulating transformers, rectifier transformers, rectifiers, busbars, filters, control, civil engineering, and other equipments. Each of these subsystems is himself divided into subassemblies and components.

The system is modeled thanks to SimaPro 7.2 software. Beside the specific data from Alstom grid, the $\mathrm{LCl}$ data come from Ecoinvent V2.1 database [16]. The LCIA results are calculated with the ReCiPe 2008 midpoint $(\mathrm{H}) \mathrm{V} 1.03$ methodology [18]. Data inventory and data quality are managed thanks to the $\mathrm{LCl}$ procedure mentioned in Section 2.2.

\subsection{Life Cycle Inventory}

\subsubsection{Data inventory}

A major characteristic of Alstom Grid electrolysis substations is that the rectifiers only are designed at the PEM units. The other equipments are designed either by other Alstom Grid units or by suppliers or subcontractors. Thus PEM is mainly a systems integrator. This means that lots of data are not directly available or even not available at all (people do not respond for confidentiality reasons).

Consequently different data sources have been used:

- Internal Alstom Grid data

- Data from suppliers, subcontractors or other units

- Generic data (from LCA databases or literature)

Specific data have been collected in a large Excel sheet. They mainly concern the following elements: masses, distribution, energy consumptions and end-of-life. Materials extraction and production, energy production and distribution as well as other data are generic.

\subsubsection{Limitations}

Mainly because of data availability, some limitations have appeared concerning the Life Cycle Inventory. The main limitation is that manufacturing processes and surface finishing have not been taken into account. Actually the data were not available for all component and materials. In order not to introduce an imbalance between the concerned equipments and the other ones, manufacturing processes and surface finishing have been dismissed. This choice is compatible with our objectives, because we aim at identifying the major environmental impacts on a large system; we prioritize a simplified and global modeling with regard to an extremely detailed and time-consuming one. The time spent to localize the data might not be profitable compared to the quality improvement of the modeling. This limitation has to be kept in mind to avoid too specific analysis of the results.

Concerning the distribution phase, only the transportation from the subsystems manufacturing site to the installation site has been considered. These transports use trucks and freight ships.

Another limitation that needs to be mentioned is the "frozen" use phase. Actually the maintenance operations, dysfunctions, upgrades or revampings are not regular and easily foreseeable. Further works are currently planned to develop a more precise life cycle modeling.

Finally, great uncertainties exist for the end-of-life phase: a simplified and possible scenario has only been modeled to illustrate what it could bring to the overall life cycle (reuse of metals and wood, recycling of transformer oil, average waste scenarios for the other components). Two reasons explain this limitation: 
- The end-of-life is currently supported by the aluminium producers, not the substations suppliers. It varies a lot from a country to another because of the regulations, environmental considerations or industrial habits.

- The end-of-life of a substation operates more than 30 years after its installation. In the developing countries in particular a 30 years vision for the recycling sector for example seems not real.

Keeping in mind these limitations, the next paragraph analyzes the main results of the LCI.

\subsubsection{Results}

Table 2 and Table 3 present the mass and energy balance sheets for the Hindalco Mahan substation. Figures have been voluntarily adapted (+/- $10 \%)$ for confidentiality reasons.

In terms of mass, the civil engineering is by far the most impacting subsystem with almost $68 \%$ of the total substation mass. By removing the civil engineering from the substation, the total mass becomes about 2900 tons, for which more than two thirds are realized by the transformers. The busbars and, to a lower extent, the rectifiers are also not negligible.

Table 2. Mass balance sheet of the substation

\begin{tabular}{lrr}
\hline \multicolumn{1}{c}{ Subsystems } & Total mass (t) & Contribution (\%) \\
\hline Substation & $\mathbf{8 8 4 5}$ & $\mathbf{1 0 0 \%}$ \\
\hline 1. Regulating transformers & 1000 & $11.3 \%$ \\
\hline 2. Rectifier transformers & 1100 & $12.4 \%$ \\
\hline 3. Rectifiers & 120 & $1.4 \%$ \\
\hline 4. Busbars & 550 & $6.2 \%$ \\
\hline 5. Filters & 25 & $0.3 \%$ \\
\hline 6. Control & 20 & $0.2 \%$ \\
\hline 7. Civil engineering & 6000 & $67.8 \%$ \\
\hline 8. Other equipments & 30 & $0.4 \%$ \\
\hline
\end{tabular}

Table 3. Energy balance sheet of the substation

\begin{tabular}{lrr}
\hline \multicolumn{1}{c}{ Subsystems } & Total losses (kW) & Contribution (\%) \\
\hline Substation & $\mathbf{8 0 0 0}$ & $\mathbf{1 0 0 \%}$ \\
\hline 1. Regulating transformers & 2400 & $30.0 \%$ \\
\hline 2. Rectifier transformers & 3200 & $40.0 \%$ \\
\hline 3. Rectifiers & 1500 & $18.8 \%$ \\
\hline 4. Busbars & 550 & $6.9 \%$ \\
\hline 5. Filters & 350 & $4.3 \%$ \\
\hline 6. Control & 0 & $0 \%$ \\
\hline 7. Civil engineering & 0 & $0 \%$ \\
\hline 8. Other equipments & 0 & $0 \%$ \\
\hline
\end{tabular}

Concerning energy (losses during operation), the rectifier transformers, regulating transformer and rectifiers are respectively the three most impacting subsystems. The electrical losses of control, civil engineering and other equipments are considered as negligible. 
It appears from these quick statements that electrical losses and masses are not correlated. It illustrates well the size and the complexity of the substation. Next paragraph will now present the potential environmental impacts associated to this inventory.

\subsection{Life Cycle Impact Assessment}

\subsubsection{Life Cycle overview}

Figure 4 gives an overview of the potential environmental impacts of the substation whole life cycle with a breakdown by life cycle phases. It appears that the use phase is responsible for more than 95 $\%$ of the total impacts, except for three impact categories: ozone depletion, ionizing radiation, metal depletion. For these categories, the contribution of the materials phase is higher. This is mainly due to metal production (steel, copper, aluminium), as well as PTFE production for ozone depletion. PTFE is included in the diodes of the rectifiers.

The domination of the use phase is clearly due to the production of electricity from coal, which is particularly polluting. Figure 4 also shows that the distribution phase is almost negligible (that is why it will not be detailed in this paper). The end-of-life phase permits to avoid less than $10 \%$ (see small green bars below the horizontal axis) of the total impacts (let remember that only a basic end-of-life scenario has been modeled). It is also not further discussed in this paper.

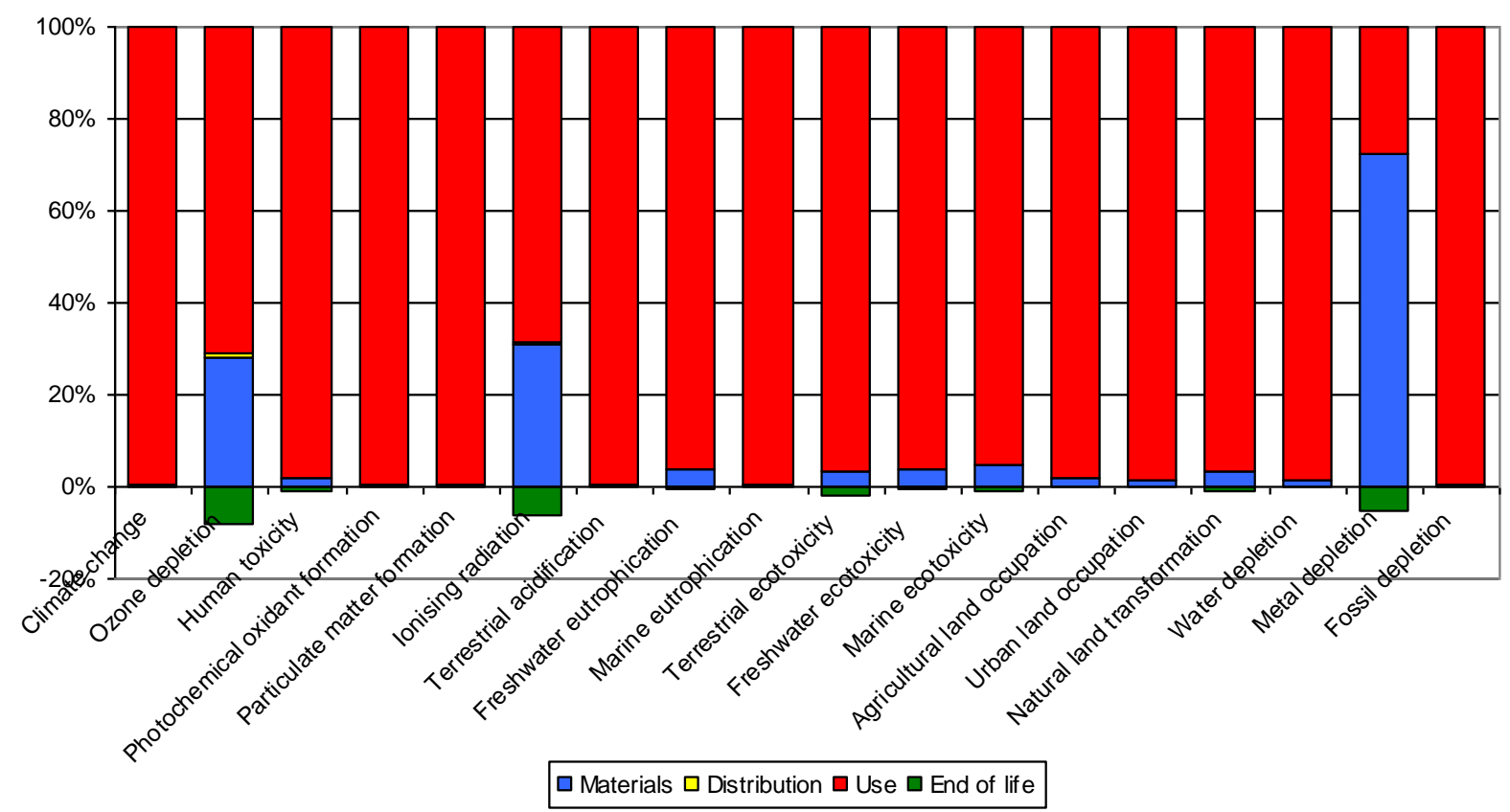

Figure 4. Breakdown by life cycle phases of the substation life cycle impacts

By considering the contribution of each subsystem to the substation life cycle, it appears that the regulating and rectifier transformers are responsible for about $70 \%$ of the total impacts, except for the three categories that were already highlighted in Figure 4. For ozone depletion, the contribution of the rectifiers is higher because of PTFE production. For ionizing radiation, the contribution of the busbars is higher, which is due to primary aluminium production (the generic data concerning the energy used for aluminium production include a part of nuclear electricity). The higher contribution of the transformers for metal depletion is caused by the high amount of copper used in their active parts.

For the other impact categories, the rectifiers account for about $19 \%$ of the impacts, while the busbars represent between 7 and $10 \%$ and the filters between 4 and $5 \%$. The other subsystems (control, civil engineering and other equipments) are negligible. 


\subsubsection{The materials phase}

Figure 5 presents the breakdown by subsystems of the impacts associated with the materials phase. The busbars (550 tons of primary aluminium) are with the regulating and rectifiers transformers the most impacting subsystems. However three impact categories present singular results: ozone depletion, agricultural land occupation, and metal depletion.

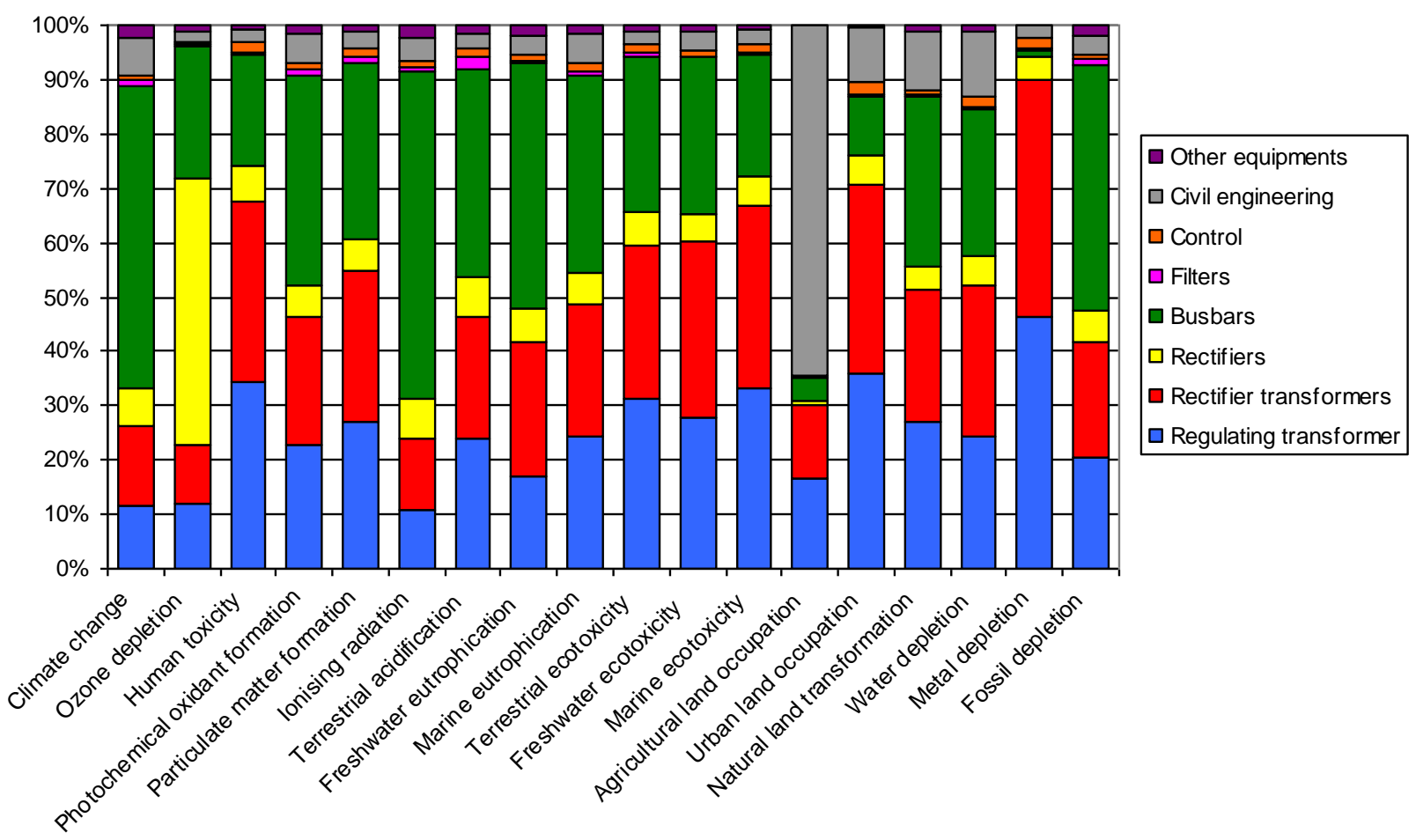

Figure 5. Breakdown by subsystems of the materials phase impacts

As previously the PTFE in the rectifier diodes explains the singularity on ozone depletion. For agricultural land occupation the civil engineering is responsible for more than $60 \%$ of the total impacts. This is mainly due to the high amount of concrete. Finally, the transformers represent $90 \%$ of the impacts on metal depletion. This value is due to the high quantity of copper used in the active parts. Actually due to the currently known resources, the characterization factor for this impact category is much bigger for copper than for aluminium [18], which explains the low score of the busbars.

The summation of the impacts generated by the transformers, rectifiers, busbars and civil engineering reaches more than $95 \%$ of the total impacts of the materials phase. The other subsystems (filters, control and other equipments) are negligible.

\subsubsection{The use phase}

As the electricity used by these subsystems comes from the same source (a coal power plant), the contribution of the subsystems is the same for every impact category and corresponds to their contribution to the electrical losses (see Table 3). Thus the electrical losses of the rectifiers and transformers represent about $89 \%$ of the total losses. The most impacting subsystem is the rectifier transformers, with $40 \%$ of the impacts.

\subsubsection{Synthesis}

Those results show that with an electrical supply by a coal power plant, the use phase largely dominates the environmental impacts. The contribution of the materials phase stays low, except on 
three impact categories: ozone depletion, ionizing radiation, and metal depletion. The distribution is negligible.

Some materials which are particularly impacting for the environment have also been highlighted, like PTFE in the rectifier diodes, or, of course, the different metals (steel, copper, aluminium) or the concrete. In this case, classical eco-design strategies are the identification of substitute materials and the decreasing of the components masses and numbers. More in-depth analysis could permit to identify other materials or components that can be taken into account for further eco-design projects.

From these LCA results, one question that quickly appears is how to value them towards the client. The next section proposes an original approach to value the results based on parametric simulations.

Thus it appears that minimizing the electrical losses during the use phase is the best way to improve the environmental performance of the substation. For instance a classical strategy in eco-design to reach this objective is to increase the section of the conductors or to minimize their length.

\section{To go further with parametric simulations}

In order to identify the best configuration of a substation from its implementation context, a first and simple model of parametric LCA simulations is presented in this section. This short study will give the first elements that will be deepened in further works.

\subsection{Towards parametric environmental models to configure complex industrial systems}

The Life Cycle Assessment of the Hindalco Mahan substation has given us the opportunity to identify environmental improvements ways (innovation leads) that will be followed in R\&D projects. The realization of these projects will give a "catalog" of eco-designed technological solutions. But the fact is that some of these solutions are maybe not compatible. Moreover nothing gives the guarantee that the optimal configuration is the assembly of all the eco-designed solutions (the global optimum is not necessarily the sum of the local optima).

Furthermore the choices made by the aluminium producers before the design of the substation are often dominant to assess its environmental impacts. The most striking example is the choice of the energy source.

Finally, the environmental considerations are clearly not the most influencing parameters in the industrial world. Economic costs, reliability, technical feasibility or quality are other criteria that are often predominant.

That is why we propose to develop in a first step parametric environmental profile simulations. From factors featuring the implementation context and/or some design parameter or design choice factors, such a tool would permit to define the optimal substation configuration among multiple response variables (including environmental performance). The technical knowledge of the designer is required to assess the consequences of the changing of a factor level on the system. This principle is explained on Figure 6.

Two complementary approaches could be developed:

- The first one will ensure the best "global" configuration from the client specifications at the call for tender stage. Input variables can be: energy source, voltage/intensity to supply, number of groups... As these are constraints fixed by the customer or issued from the environment, they are called exogenous parameters. In this global configuration, the exogenous parameters 
permit to define the best optimum for the main endogenous parameters (i.e. that are mastered by the actors of the system).

- The second one will ensure the best "detailed" configuration from the global configuration previously defined. Input variables can be: number of diodes per rectifier arm, transformer oil, busbars section... From the main endogenous parameters fixed during the global configuration, the detailed configuration permits to fix the other endogenous design parameters.

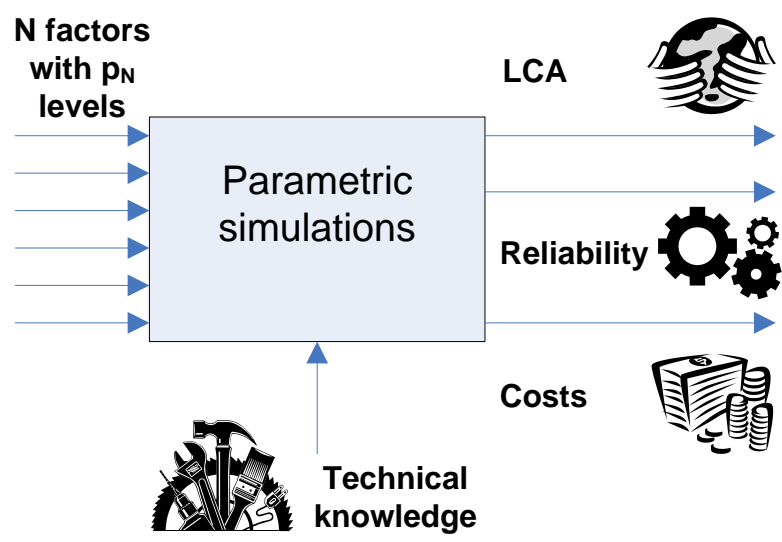

Figure 6. Principle of the proposed model

The next paragraph proposes to illustrate what a parametric LCA simulation can be with a very simple example based on a single factor and a single response.

\subsection{Preliminary study: one factor with four levels}

In this paragraph one input factor (electricity source) with four levels (electricity from coal, electricity from natural gas, hydroelectricity, and nuclear electricity) will be considered. Electricity from coal corresponds to the Hindalco Mahan substation that was previously assessed.

The environmental performance of the substation will be considered as response. In fact, this is a multi-objective response, because of the 18 impact categories composing the LCIA results with the ReCiPe 2008 method. For this simple application, the 7 most important categories with the LCIA normalized results have been chosen.

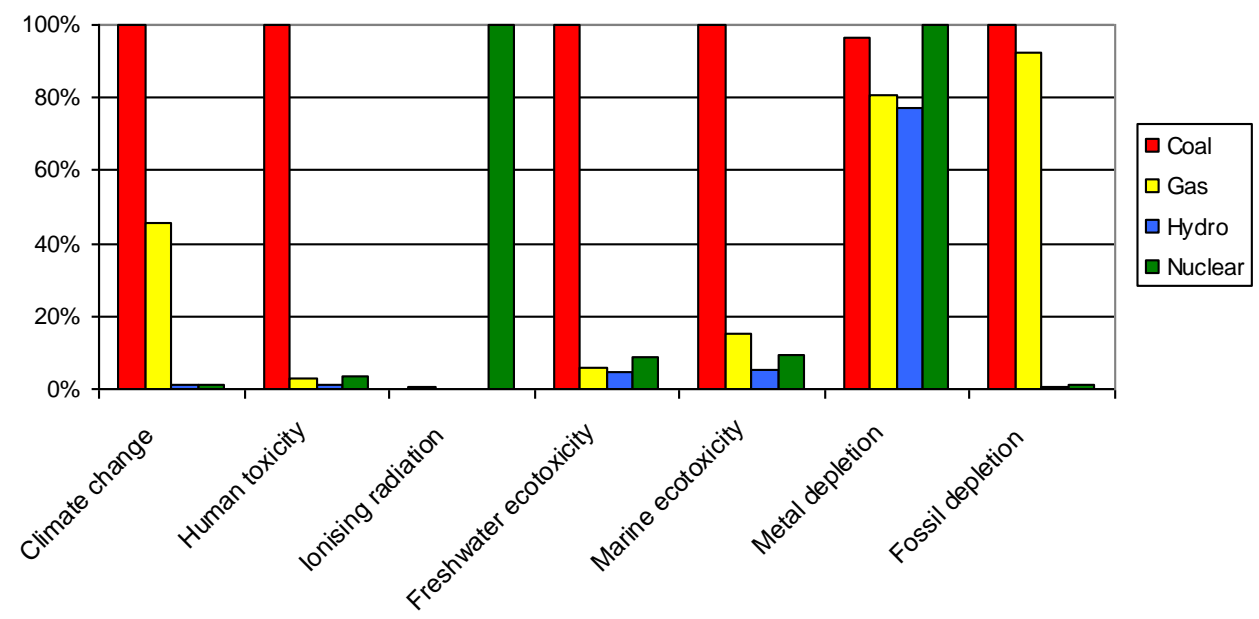

Figure 7. Comparison of the four electricity sources scenarios for the whole substation life cycle 
Figure 7 shows the comparison of the environmental impacts for the four levels. $100 \%$ represents the highest value among the four levels. If the hydro scenario is clearly the best alternative, it is more difficult to separate the three other scenarios. For example the nuclear scenario is the worst one on ionizing radiation and (only just) metal depletion. The coal scenario reaches the highest values for the other categories. The natural gas scenario is never the worst, but is for example higher than the nuclear scenario on climate change and lower on metal depletion.

The question that appears is then: is it possible to rank the four alternatives? Except for the hydro scenario which is the best one, it is not possible without a weighting of the categories. Such a weighting can be made by the customers considering their own environmental considerations. For example, climate change is clearly one of the main environmental issues for aluminium producers [19].

The comparison between the breakdown by life cycle phases for the hydro scenario and the coal scenario gives the most interesting results. It appears that the contribution of the use phase has largely decreased from the hydro scenario. This means that the materials phase is now responsible for most than $50 \%$ of the total life cycle impacts on most of the impact categories. Moreover the gas and nuclear scenarios show intermediary results between the hydro and coal scenarios.

This is an extremely important result, which shows that the eco-design activities or the configuration choice stemming from the analysis of these environmental profiles may be different from one substation to another. Actually in the Hindalco Mahan case (electricity from coal), the decreasing of the electrical losses is the best way to improve the overall environmental performance of the substation. Impact transfers from the use phase to the materials phase can be acceptable if the environmental benefits are significant. On the contrary, in a Canadian case (hydroelectricity), minimizing weights and substituting materials can bring significant benefits. If the optimal configuration clearly depends on classical design parameters (endogenous parameters), this very simple design of experiments shows that the optimal configuration of a substation also depends on local parameters that are chosen by the clients (exogenous parameters). Thus they have to be taken into account in an environmental perspective. A more advanced model based on design of experiments and mixing endogenous and exogenous parameters could be a powerful tool to value eco-design towards customers. Such a model will be developed in the next months.

\section{6. conclusions and perspectives}

We have shown in this paper that conducting a Life Cycle Assessment of a complex industrial system is in itself complex. Limitations and simplifications are mandatory to reach satisfactory results with acceptable time and resources. Such a LCA permits to draw global conclusions and to envisage more advanced eco-design activities. More refined analysis on the subsystems must however be considered with precaution in view of the data granularity. But this global approach could be a powerful basis to indepth studies on a particular life cycle phase or subsystem for example.

In this way the LCA of an Alstom Grid AC/DC conversion substation for the primary aluminium industry presented in this paper gives a strong basis to further works. The substations main environmental issues have been clearly identified as well as the limitations of our approach. The principal limit is probably the "frozen" use phase, since maintenance, dysfunctions, updates and real life times have not been taken into account. We are currently working on a sharp parameterization of the LCA modeling to draw different usage scenarios and reach more precise analysis. In the Alstom Grid context, those LCA results and creativity sessions have already permitted to identify about fifteen promising improvement projects.

Furthermore the LCA results analysis has allowed us to imagine parametric environmental simulations to identify the best substation configuration from a given implementation context. A very simple 
approach with a single factor has shown that the electricity source for example is a crucial factor to orient eco-design actions and optimize the substation configuration. We are convinced that this kind of tool is essential to ensure a good demarcation from the competitors and to drive continuous improvement on eco-design in the company. A preliminary model will be developed in the next months to prove these assertions.

The principle of this more advanced model with several factors is the following: by mixing endogenous and exogenous parameters as input variables, it will be possible thanks to design of experiments to build a response surface to define the optimal configurations. By fixing the exogenous parameters from the customer requirements, it will be possible to choose the best endogenous parameters.

In a first step a model restricted to an Alstom Grid rectifier will be developed with one exogenous parameter (electricity source, as previously) and two endogenous parameters: the number of diodes per rectifier arm (which a dimensioning parameter for the rectifier) and the rectifier frame material. The variation of these two parameters influences both the electrical losses and the mass of the system. As response the economic cost (life cycle cost to include the electrical losses costs) and the reliability will be added to the environmental performance. This model will be a demonstrator to prove the possibilities of a more sophisticated configurator for commercial use.

\section{Acknowledgments}

We gratefully thank Joël Devautour and François Puchar from Alstom Grid for their full support to this work. We also thank Daniel Afonso from CUBIK Partners for his contribution to the methodological aspects, as well as Anthony Rolland for his supplies to the LCA results.

\section{References}

[1] European Union, 2003, Directive 2002/96/EC of the 27 January 2003 on waste electrical and electronic equipment (WEEE).

[2] European Union, 2003, Directive 2002/95/EC of the 27 January 2003 on the restriction of the use of certain hazardous substances in electrical and electronic equipment.

[3] European Union, 2005, Directive 2005/32/EC of 6 July 2005 establishing a framework for the setting of ecodesign requirements for energy-using products.

[4] European Union, 2006, Regulation (EC) $n^{\circ} 1907 / 2006$ of the European Parliament and of the Council of 18 December 2006 concerning the Registration, Evaluation, Authorisation and Restriction of Chemicals (REACH).

[5] Dewulf W., 2003, "A pro-active approach to ecodesign: framework and tools," PhD Thesis, Katholieke Universiteit Leuven.

[6] Reap J., Roman F., Duncan S., and Bras B., 2008, "A survey of unresolved problems in life cycle assessment - Part 1: goal and scope and inventory analysis," The International Journal of Life Cycle Assessment, 13(4), pp. 290-300.

[7] Reap J., Roman F., Duncan S., and Bras B., 2008, "A survey of unresolved problems in life cycle assessment - Part 2: impact assessment and interpretation," The International Journal of Life Cycle Assessment, 13(5), pp. 374-388.

[8] International Organization for Standardization, 2006, ISO 14040:2006 - Environmental management - Life cycle assessment - Principles and framework. 
[9] International Organization for Standardization, 2006, ISO 14044:2006 - Environmental management - Life cycle assessment - Requirements and guidelines.

[10] Weidema B. P., and Wesnæs M. S., 1996, "Data quality management for life cycle inventories-an example of using data quality indicators," Journal of Cleaner Production, 4(3-4), pp. 167-174.

[11] Leroy Y., 2009, "Development of a methodology to reliable environmental decision from Life Cycle Assessment based on analysis and management of inventory data uncertainty," PhD Thesis, Ecole Nationale Supérieure d'Arts et Métiers, Chambéry, France.

[12] Millet D., Bistagnino L., Lanzavecchia C., Camous R., and Poldma T., 2007, "Does the potential of the use of LCA match the design team needs?," Journal of Cleaner Production, 15, pp. 335-346.

[13] Cluzel F., Yannou B., Afonso D., Leroy Y., Millet D., and Pareau D., 2010, "Managing the complexity of environmental assessments of complex industrial systems with a Lean 6 Sigma approach," Proc. CSDM 2010, Complex Systems Design and Management 2010, Paris, France.

[14] Schmidt J., and Thrane M., 2009, "Life cycle assessment of aluminium production in new Alcoa smelter in Greenland."

[15] Macharey U., Schnettler A., and Smolka T., 2007, "Life Cycle Assessment of Ultra High Voltage system layout and operation compared to $420 \mathrm{kV}$ AC power systems," IEC/CIGRE UHV Symposium, Beijing, China.

[16] Ecoinvent, 2007, "Overview and Methodology - Data v2.0 (2007)."

[17] Leroy C., 2009, "Provision of LCl data in the European aluminium industry Methods and examples," The International Journal of Life Cycle Assessment, 14(0), pp. 10-44.

[18] Goedkoop M., Heijungs R., Huijbregts M., De Schryver A., Struijs J., and Van Zelm R., 2009, "ReCiPe 2008 - A life cycle impact assessment method which comprises harmonised category indicators at the midpoint and the endpoint level - First edition - Report I: Characterisation."

[19] Wuppertal Institute, and Triple Innova, 2004, "Toward a Sustainable Aluminium Industry: Stakeholder Consultations - Final Report." 